\title{
Review on 5G Wireless Technology
}

\author{
Ravali Kolli ${ }^{1}$, Swetha Mile ${ }^{2}$, Shreya Shetty ${ }^{3}$, Dr. Sunanda Dixit ${ }^{4}$ \\ Student, Department of Information Science and Engineering, Dayananda Sagar College of Engineering, Bangalore, \\ Karnataka, India ${ }^{1,2,3}$ \\ Associate Professor, Department of Information Science and Engineering, Dayananda Sagar College of Engineering, \\ Bangalore, Karnataka, India ${ }^{4}$
}

\begin{abstract}
G technology is a revolutionary technology in the field of wireless telecommunications implementing the latest networking architecture which provides high quality services. In this paper, an attempt is made to review the existing generations of mobile wireless technology, their evolution and compare them in terms of their features and performances. Efforts are made to shed light on the architecture proposed by far for the implementation of a 5G network. The term 5G is used alternatingly with World Wide Wireless Web (WWWW), which as a platform enables us to connect to any kind of devices, anytime, anywhere.
\end{abstract}

Keywords: 5G, 5G architecture, Evolution of 5G, 5G design.

\section{INTRODUCTION}

The world has seen a great deal of changes in the domain of Communication. Over the previous decade, wireless services and technologies have drastically developed while forming our economy and society. We've moved from simple to computerized, from voice only services to wireless broadband, from $2 \mathrm{G}$ to $4 \mathrm{G}$, and beyond [1].

Technological innovation both supports and stretches the boundaries of flexible use policies, permitting a lot of uses and users to be. This can be true just in case of $5 \mathrm{G}$ technologies that allows higher-spectrum bands for quality than previously thought potential.

5G (5th generation mobile networks or 5th generation wireless systems) denotes the proposed next major phase of mobile telecommunication standards beyond the current 4G/IMT Advanced standards. 5G planning incorporates Internet connection speeds faster than current $4 \mathrm{G}$, and other improvements.

The fifth generation wireless mobile multimedia internet networks can be completely wireless communication without limitation, which makes perfect wireless real world - World Wide Wireless Web (WWWW). It is based on $4 \mathrm{G}$ technologies. The 5 th wireless mobile internet networks are real wireless world which shall be supported by LAS-CDMA (Large Area Synchronized Code-Division Multiple Access), OFDM (Orthogonal frequency-division multiplexing), MC CDMA (Multi-Carrier Code Division Multiple Access), UWB (Ultra-wideband), NetworkLMDS (Local Multipoint Distribution Service), and IPv6. Fifth generation technologies offers gigantic information capabilities and unlimited call volumes and infinite data broadcast within latest mobile operating systems. It is ought to have a critical effect and add more administrations and advantages to the world more than 4G. This generation is expected to be released around 2020. This world of universal, uninterrupted access to information, entertainment and communication will open new dimension to our lives and change our way of life significantly [2].

\section{EVOLUTION}

\section{A. First Generation (1G)}

$1 \mathrm{G}$ was developed in the 1980 's. It contains analog system which supported the 1st generation of analog cell phones with speed up to $2.4 \mathrm{kbps}$.It introduces mobile technologies such as mobile telephone system (MTS), Advanced mobile telephone system (AMTS), Improved mobile telephone system (IMTS) and push to talk (PTT).It uses analog radio signal which have frequency $150 \mathrm{MHz}$.Voice call modulation is done using a technique called frequency division multiple access (FDMA). It allows users to make voice calls in 1 country. But it had low capacity, unreliable handoff, poor voice links and no security at all since voice calls were played back in radio towers making these calls susceptible to unwanted eavesdropping by third parties [3].

\section{B. Second Generation (2G)}

$2 \mathrm{G}$ emerged in late 1990s. Commercially launched on the GSM standard in Finland (1991). It uses digital signals for voice transmission and has speed of $64 \mathrm{kbps}$. $2 \mathrm{G}$ network allows for much greater penetration intensity and provides services such as text messages, picture messages and Multimedia Messaging Service (MMS) which uses the bandwidth of 30 to $200 \mathrm{KHz}$. Text messages are digitally encrypted. Next to $2 \mathrm{G}, 2.5 \mathrm{G}$ system uses packet switched and circuit switched domain and provide data rate up to $144 \mathrm{kbps}$.

E.g. GPRS, CDMA and EDGE [2].

\section{Third Generation (3G)}

It uses Wideband Wireless Network with which clarity is increased. The data are sent through the technology called 
Vol. 5, Issue 12, December 2016

Packet Switching. Voice calls are interpreted through D. Fourth Generation (4G)

Circuit Switching. Along with verbal communication it $4 \mathrm{G}$ offers both cellular and broadband multimedia services includes data services, access to television/video, new everywhere. It offers a downloading speed of $100 \mathrm{Mbps} .4 \mathrm{G}$ services like Global Roaming. Data Transmission speed provides same feature as $3 \mathrm{G}$ and additional services like ranges from $125 \mathrm{kbps}$ to $2 \mathrm{Mbps}$. It operates at a range of Multi- Media Newspapers, to watch T.V programs with $2100 \mathrm{MHz}$ and has a bandwidth of $15-20 \mathrm{MHz}$ used for more clarity and send Data much faster than previous High-speed internet service, video chatting.3G uses Wide generations [4]. LTE (Long Term Evolution) is considered Band Voice Channel due to which the world has been as 4G technology. 4G is being developed to accommodate contracted to a little village because a person can contact the QoS and rate requirements set by forthcoming with other person located in any part of the world and can applications like wireless broadband access, MMS, video send messages too [4]. chat, mobile TV, HDTV content, Digital Video Broadcasting (DVB), minimal services like voice and data, and other services that utilize bandwidth [5].

Table I: Evolution of generation and their features [6]

\begin{tabular}{|c|c|c|c|c|c|}
\hline $\begin{array}{c}\text { Generation } \rightarrow \\
\text { Features } \downarrow\end{array}$ & $1 \mathrm{G}$ & $2 \mathrm{G}$ & $3 \mathrm{G}$ & $4 \mathrm{G}$ & $5 \mathrm{G}$ \\
\hline Deployment & $1970-1980$ & $1990-2001$ & $2001-2010$ & 2011 & $2015-20$ onwards \\
\hline Data Rates & $2 \mathrm{kbps}$ & $14.4-64 \mathrm{kbps}$ & $2 \mathrm{Mbps}$ & $\begin{array}{c}200 \mathrm{Mbps} \text { to } 1 \\
\text { Gbps }\end{array}$ & $1 \mathrm{Gbps}$ and higher \\
\hline Technology & $\begin{array}{l}\text { Analog Cellular } \\
\text { Technology }\end{array}$ & $\begin{array}{c}\text { Digital Cellular Technology: } \\
\text { Digital narrow band } \\
\text { circuit data } \\
\text { Packet data }\end{array}$ & $\begin{array}{c}\text { Digital Broadband } \\
\text { Packet data: } \\
\text { CDMA 2000 } \\
\text { EVDO } \\
\text { UMTS } \\
\text { EDGE }\end{array}$ & $\begin{array}{c}\text { Digital } \\
\text { Broadband } \\
\text { Packet data: } \\
\text { WiMax LTE } \\
\text { Wi-Fi }\end{array}$ & $\begin{array}{c}\text { wwwww Unified IP } \\
\text { seamless } \\
\text { combination of } \\
\text { broadband } \\
\text { LAN } \\
\text { PAN } \\
\text { MAN } \\
\text { WLAN }\end{array}$ \\
\hline Service & $\begin{array}{l}\text { Analog voice } \\
\text { service } \\
\text { No data service }\end{array}$ & $\begin{array}{l}\text { Digital voice with higher clarity } \\
\text { SMS, MMS } \\
\text { Higher capacity packetized data }\end{array}$ & $\begin{array}{c}\text { Enhanced audio video } \\
\text { streaming } \\
\text { video conferencing } \\
\text { support } \\
\text { Web browsing at } \\
\text { higher speeds } \\
\text { IPTV support } \\
\end{array}$ & $\begin{array}{l}\text { Enhanced } \\
\text { audio, video } \\
\text { streaming } \\
\text { IP telephony } \\
\text { HD mobile TV }\end{array}$ & $\begin{array}{c}\text { Dynamic } \\
\text { Information } \\
\text { access, } \\
\text { Wearable devices } \\
\text { with AI } \\
\text { Capabilities }\end{array}$ \\
\hline $\begin{array}{l}\text { Multiplexing } \\
\text { Switching }\end{array}$ & FDMA & TDMA, CDMA & CDMA & CDMA & CDMA \\
\hline Core Network & PSTN & PSTN & Packet N/W & Intemet & Intemet \\
\hline Standards & $\begin{array}{l}\text { MTS } \\
\text { AMTS } \\
\text { IMTS }\end{array}$ & $\begin{array}{c}\text { 2G:GSM } \\
\text { 2.5:GPRS } \\
2.75: \text { EDGE }\end{array}$ & $\begin{array}{c}\text { IMT-2000 } \\
\text { 3.5G-HSDPA } \\
\text { 3.75G:HSUPA }\end{array}$ & $\begin{array}{l}\text { Single unified } \\
\text { standard } \\
\text { LTE, } \\
\text { WiMAX }\end{array}$ & $\begin{array}{l}\text { Single unified } \\
\text { standard }\end{array}$ \\
\hline WEB Standard & & $\mathrm{wwww}$ & wwww(IPv4) & wwww (IPv4) & wwww (IPv6) \\
\hline Handoff & Horizontal only & Horizontal only & Horizontal \& Vertical & $\begin{array}{c}\text { Horizontal \& } \\
\text { Vertical }\end{array}$ & $\begin{array}{c}\text { Horizontal \& } \\
\text { Vertical }\end{array}$ \\
\hline Shortfalls & $\begin{array}{c}\text { Low capacity, } \\
\text { Unreliable handoff, } \\
\text { Poor voice links, Less } \\
\text { secure } \\
\end{array}$ & $\begin{array}{l}\text { Digital signals were reliant on } \\
\text { location \& proximity, required } \\
\text { strong digital signals to help } \\
\text { mobile phones }\end{array}$ & $\begin{array}{l}\text { Need to a ccommodate } \\
\text { higher network } \\
\text { capacity }\end{array}$ & Being deployed & $\begin{array}{l}\text { Yet to be } \\
\text { implemented }\end{array}$ \\
\hline
\end{tabular}

\section{SALIENT FEATURES OF 5G}

- The technology 5G presents the high resolution for sharp, passionate cell phone every day and give consumers well shape and fast Internet access.

- The 5G technology provides billing limits in advance that the more beautiful and successful of the modern era.

- The 5G technology also allows users of mobile phones, cell phone records for printing operations.

- The 5G technology for large volume data distribution in Gigabit, which also maintains close ties to almost 65,000 .

- The information from the data transfer technology $5 \mathrm{G}$ organize a more accurate and reliable results.

- Using remote control technology to get the consumer can also get a $5 \mathrm{G}$ comfort and relax by having a better speed and clarity in less time alone.

- The 5G technology also support virtual private network.
- The uploading and downloading speed of 5G technology touching the peak.

- The 5G technology network offering enhanced and available connectivity just about the world

- $5 \mathrm{G}$ network is very fast and reliable [7].

\section{5G DESIGN AND ARCHITECTURE}

E. Design

5G would be about "ubiquitous computing". Human life will be surrounded by intelligent sensors, which will bring radical change to human life's daily approaches of doing things. Existing telecom networks are fashioned in hierarchical way, where subscriber traffic is aggregated at aggregation point Base Station Controller/Radio Network Controller (BSC/RNC) and then routed to gateways. Whereas a flat IP architecture as proposed to be used in $5 \mathrm{G}$ will lessen the burden on aggregation point and the traffic will directly move from Base station to Media gateways. Vision of Super Core is based on IP platform. All network 
Vol. 5, Issue 12, December 2016

operators (GSM, CDMA, WiMAX, and Wireline) can be we need to have four different access-specific interfaces in connected to one Super core with massive capacity. This is the mobile terminal, and to have all of them active at the realization of single network infrastructure. Flat IP same time, with aim to have this architecture to be architecture provides a way to identify devices using functional [8].

symbolic names, unlike the hierarchical architecture such as that used in "normal" IP addresses. This is of more interest to mobile broadband network operators. With the shift to flat IP architectures, mobile operators can:

- Reduce the number of network elements in the data path to lower operations costs and capital expenditure.

- Partially decouple the cost of delivering service from the volume of data transmitted to align infrastructure capabilities with emerging application requirements.

\section{F. Architecture- The Nanocore}

The 5G Nanocore is a convergence of below mentioned technologies. These technologies have their own impact on existing wireless network which makes them into 5G.

- Nanotechnology.

- Cloud Computing.

- All IP Platform.

1) Nanotechnology

- Minimize system latency and enable applications with Nanotechnology is the application of nanoscience to a lower tolerance for delay; upcoming latency control process on nanometer scale. i.e. between 0.1 and enhancements on the radio link can also be fully $100 \mathrm{~nm}$. The field is also known as molecular realized.

- Evolve radio access and packet core networks independently of each other to a greater extent than in the past, creating greater flexibility in network planning and deployment.

- Develop a flexible core network that can serve as the basis for service innovation across both mobile and generic IP access networks.

- Create a platform that will enable mobile broadband operators to be competitive, from a price/performance perspective, with wired networks. Flat network architecture removes that voice-centric hierarchy from the network. Instead of overlaying a packet data core on the voice network, separate and much-simplified data architecture can be implemented that removes the multiple elements from the network chain.

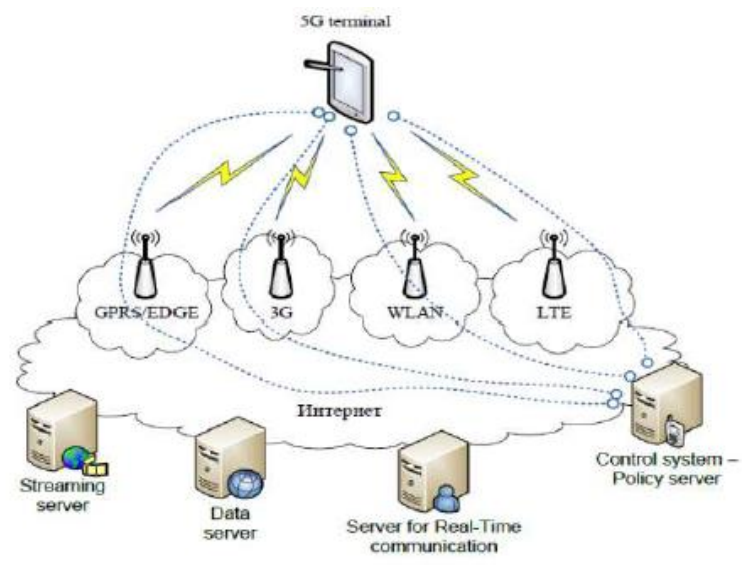

Fig.2: IP based system model of $5 \mathrm{G}$ designed for the wireless and mobile networks [9]. nanotechnology (MNT).MNT deals with control of the structure of matter based on atom-by-atom and molecule by molecule engineering.

Nanotechnology has shown its impact on both mobile as well as the core network. Apart from this it has its own impact on sensor as well as security. This is considered as a most significant in telecommunication [8].

\section{2) Nano Equipment (NE)}

In 5G Nanocore mobiles are referred as Nano Equipments as they are geared up with nanotechnology. One of the central visions of the wireless industry aims at ambient intelligence: computation and communication always available and ready to serve the user in an intelligent way. This requires that the devices are mobile. Mobile devices together with the intelligence that will be embedded in human environments - home, office, public places - will create a new platform that enables ubiquitous sensing, computing, and communication Specs of Nano Equipments given as follow:

- Self-Cleaning - the phone cleans by itself

- Self-powered - the phone derives its energy/power from the sun, water, or air.

- Sense the environment - the phone will tell you the weather, the amount of air pollution present, etc.

- Flexible

- Transparent [8].

\section{3) Cloud Computing}

Cloud computing is a technology that uses the internet and central remote server to maintain data and applications. In $5 \mathrm{G}$ network this central remote server will be our content provider. Cloud computing allows consumers and business

The system consists of a user terminal (which has a crucial role in the new architecture) and a number of independent, autonomous radio access technologies. Within each of the terminals, each of the radio access technologies is seen as the IP link to the outside Internet world. However, there should be different radio interface for each Radio Access Technology (RAT) in the mobile terminal. For an example, if we want to have access to four different RATs, personal files from any computer with internet access. The same concept is going to be used in Nanocore where the user tries to access his private account form a global content provider through Nanocore in form of cloud. Cloud computing relies on the networks, requiring secure and reliable service providers. Operators can enter the cloud computing market and create new value-added 
Vol. 5, Issue 12, December 2016

services and experiences by integrating industry content Primarily focused upon enhancements of packet switched and applications in the digital supermarket model. This technology, AIPN provides a continued evolution and could make our user to obtain much more real-time optimization of the system concept in order to provide a application to utilize his $5 \mathrm{G}$ network efficiently. Secure competitive edge in terms of both performance and cost. and reliable service can be provided with the help of quantum cryptography. Cloud computing has three main The key benefits of flat IP architectures are: segments which are as follows:

1. Applications - It is based on, on demand software services. On demand software services vary in their pricing scheme and how the software is delivered to the end users. For example the end-user would purchase a server that can be accessed by the end user over the internet.

2. Platform - The platform segment refers to the products that are used to deploy internet. NetSuite, Amazon, Google, and Microsoft have also developed platforms that allow users to access applications from centralized servers. 3. Infrastructure - The third segment in cloud computing, known as the infrastructure, is the backbone of the entire concept. Infrastructure vendor's environments such as Google gears allow users to build applications. Cloud storage, such as Amazon's S3, is also considered to be part of the infrastructure segment. 5G Nanocore will efficiently utilizes all the above 3 segments to satisfy customer demands.

\section{4) All IP Network}

As already discussed for converging different technologies to form a single 5G Nanocore, we require a common platform to interact. Flat IP architecture act as an essential part of 5G network. The All-IP Network (AIPN) is an evolution of the 3GPP system to meet the increasing demands of the mobile telecommunications market. To meet customer demand for real-time data applications delivered over mobile broadband networks, wireless operators are turning to flat IP network architectures.

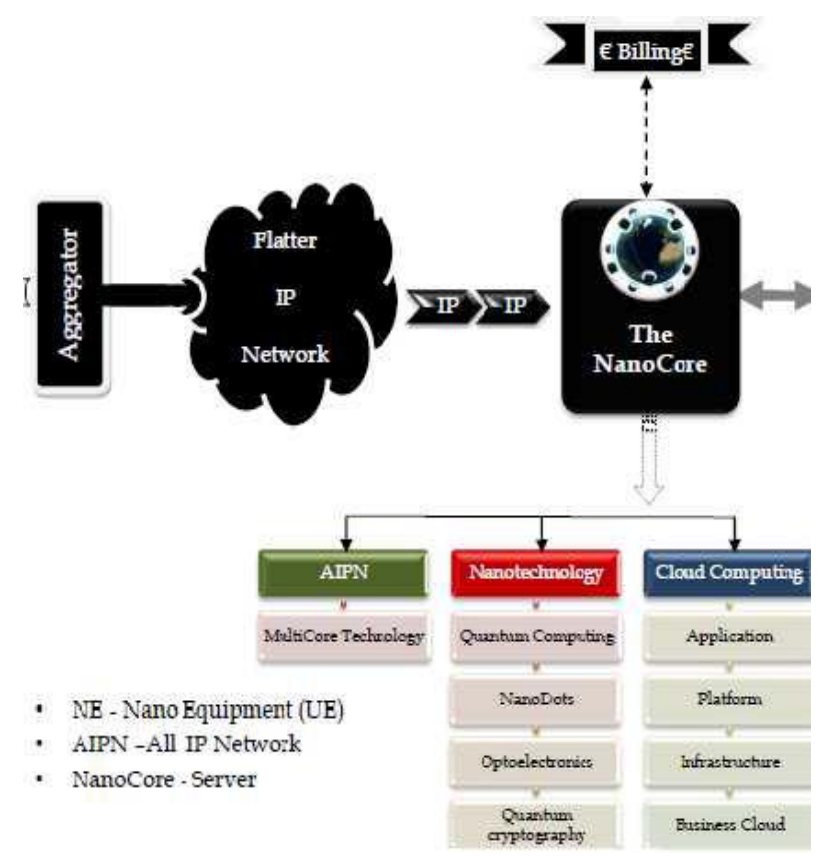

- Lower costs

- Universal seamless access

- Improved user experience

- Reduced system latency

- Decoupled radio access and core network evolution [8].

\section{5G ADVANTAGES AND DISADVANTAGES}

5th generation technology offers a wide range of features, which are beneficial for all group of people including, students, professionals (doctors, engineers, teachers, governing bodies, administrative bodies, etc.) and even for a common man.

The 5G Architecture nanocore [3] is shown above.

G. Advantages

There are several advantages of 5G technology, some of them are mentioned below

- High resolution and bi-directional large bandwidth shaping.

- Technology to gather all networks on one platform.

- More effective and efficient.

- Technology to facilitate subscriber supervision tools for the quick action.

- Most likely, will provide a huge broadcasting data (in Gigabit), which will support more than 60,000 connections.

- Easily manageable with the previous generations.

- Technological sound to support heterogeneous services (including private network).

- Possible to provide uniform, uninterrupted, and consistent connectivity across the world [9].

- More applications combined with artificial intelligent (AI) as human life will be surrounded by artificial sensors which could be communicating with mobile phones [10].

Some other advantages for common people:

- You can control your PCs by handsets.

- Parallel multiple services, such as you can know weather and location while talking with another person

- Education will become easier. Student sitting in any part of world can attend the class. Medical Treatment will become easier \& frugal and a doctor can treat the patient located in remote part of the world.

- Monitoring will be easier. Possible to locate and search the missing person. Visualizing universe, galaxies, and planets will be possible.

- Possible, natural disaster including tsunami, earthquake etc. can be detected faster [9]. 


\section{H. Disadvantages}

Though, 5G technology is researched and conceptualized to solve all radio signal problems and hardship of mobile world, but because of some security reason and lack of technological advancement in most of the geographic regions, it has following shortcomings

- Technology is still under process and research on its viability is going on.

- The speed, this technology is claiming seems difficult to achieve (in future, it might be) because of the incompetent technological support in most parts of the world.

- Many of the old devices would not be competent to $5 \mathrm{G}$, hence, all of them need to be replaced with new expensive deal.

- Developing infrastructure needs high cost.

- Security and privacy issue yet to be solved [9].

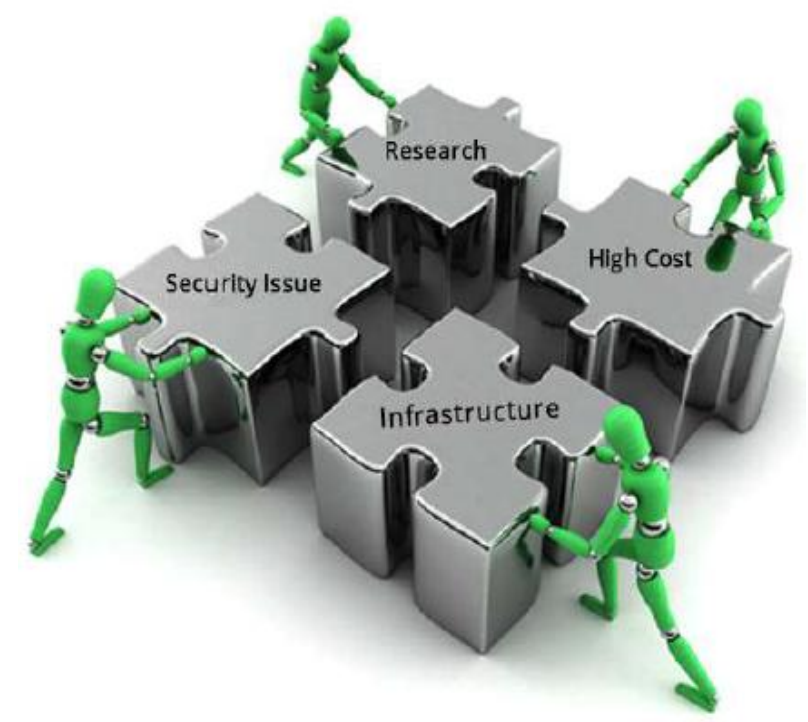

Fig.4: Key Factors in 5G

\section{CONCLUSION}

$5 \mathrm{G}$ is going to have a much tougher process behind its development level. The $5 \mathrm{G}$ network is very fast and reliable. Fifth generation is based on $4 \mathrm{G}$ technologies. With the use of IP version 6, 5G will have higher security. The development of the mobile and wireless networks is going towards higher data rates and all-IP principle. Mobile terminals are obtaining each year more processing power, more memory on board, and longer battery life for the same applications. 5G include latest technologies such as cognitive radio, Software Defined Radio (SDR), nanotechnology, cloud computing and based on All IP Platform. It is expected that the initial Internet philosophy of keeping the network simple as possible, and giving more functionalities to the end nodes, will become reality in the future generation of mobile networks, here referred to as $5 \mathrm{G}$. In this paper we have compared $1 \mathrm{G}$ to $5 \mathrm{G}$ networks along with their features.

\section{REFERENCES}

[1] AleksandarTudzarov and Toni Janevski, "Functional Architecture for "5G Mobile Networks" International Journal of Advanced Science and Technology Vol. 32, July, 2011.

[2] Ms. Neha Dumbre, Ms. MonaliPatwa, Ms. KajalPatwa, "5G WIRELESS TECHNOLOGIES-Still $4 \mathrm{G}$ auction not over, but time to start talking 5G' International Journal of Science, Engineering and Technology Research (IJSETR) Volume 2, Issue 2, February 2013.

[3] "5G Mobile Technology" by Ms. Reshma S. Sapakal and Ms. Sonali S. Kadam in International Journal of Advanced Research in Computer Engineering \& Technology (IJARCET) Volume 2, Issue 2, February 2013

[4] "5G Technology - Redefining wireless Communication in upcoming years" by Akhilesh Kumar Pachauri 1 and Ompal Singh published in International Journal of Computer Science and Management Research Vol 1 Issue 1 Aug 2012 ISSN 2278 - 733X.

[5] "5g Wireless Architecture" By Vadan Mehta.

[6] "5G Network a New Look into the Future: Beyond all Generation Networks" by Sidhartha Sankar Sahoo, Malaya Kumar Hota, Kalyan Kumar Barik.

[7] "5G Technology-Evolution and Revolution" by Meenal G. Kachhavay and Ajay P. Thakare in International Journal of Computer Science and Mobile Computing, Vol.3 Issue.3, March2014.

[8] SuvarnaPatil, VipinPatil, .Pallavi Bhatt, "A Review on 5G Technology" International Journal of Engineering and Innovative Technology (IJEIT) Volume 1, Issue 1,January 2012.

[9] "5G Tutorial" fromwww.tutorialspoint.com.

[10] "Prospective of Fifth Generation Mobile Communications" by Dr. Anwar M. Mousa of University of Palestine,Gaza- Palestine published in International Journal of Next-Generation Networks (IJNGN) Vol.4, No.3,September 2012 